\title{
A NARX Model to Predict Cabin Air Temperature to Ameliorate HVAC Functionality
}

\author{
Srikanth Kolachalama *(D) and Hafiz Malik \\ Electrical and Computer Engineering, University of Michigan, Dearborn, MI 48128, USA; hafiz@umich.edu \\ * Correspondence: skola@umich.edu
}

Citation: Kolachalama, S.; Malik, H. A NARX Model to Predict Cabin Air Temperature to Ameliorate HVAC Functionality. Vehicles 2021, 3, 872-889. https://doi.org/10.3390/ vehicles3040052

Academic Editor: Giulio Reina

Received: 23 October 2021

Accepted: 30 November 2021

Published: 3 December 2021

Publisher's Note: MDPI stays neutral with regard to jurisdictional claims in published maps and institutional affiliations.

Copyright: (c) 2021 by the authors. Licensee MDPI, Basel, Switzerland. This article is an open access article distributed under the terms and conditions of the Creative Commons Attribution (CC BY) license (https:/ / creativecommons.org/licenses/by/ $4.0 /)$.

\begin{abstract}
Vehicular technology has integrated many features in the system, which enhances the safety and comfort of the user. Among these features, heating, ventilation, and air conditioning (HVAC) is the only feature that maintains the set cabin air temperature (CAT). The user's command drives the set CAT, and the thermostat provides feedback to the HVAC to maintain the set CAT. The CAT is increased by extracting the heat from the engine surface produced by the fuel combustion, whereas the CAT is reduced by the known processes of the air conditioning system (ACS). Therefore, the CAT driven by the user's command may not be optimal, and estimating the optimal CAT is still unsolved. In this work, we propose a new process where the user can input a range for CAT instead of a single value. Optimal HVAC criteria were defined, and the CAT was estimated by performing iterative analysis in the user-selected range satisfying the criteria. The HVAC criteria were defined based on two measurable parameters: air conditioning refrigerant fluid pressure (ACRFP) and engine surface temperature (EST) empirically defined as the vector CATOP. In this article, a NARX DL model was used by mapping the vehicle-level vectors (VLV) to predict the CATOP in real-time using field data obtained from a 2020 Cadillac CT5 test vehicle. Utilising the DL model, CATOP for future time steps was predicted by varying the CAT in the definite range and applying HVAC criteria. Thus, an optimal set CAT was estimated, corresponding to the optimal CATOP defined by the HVAC criteria. We performed the validation of the DL model for multiple datasets using traditional statistical techniques, namely, signal-to-noise ratio (SNR) values, first-order derivatives (FOD), and root-mean-square error (RMSE).
\end{abstract}

Keywords: deep learning; HVAC; cabin air temperature; driver behaviour; NARX

\section{Introduction}

The automotive industry's evolution has influenced every engineering aspect, including materials science, thermal engineering, and control theory [1]. In an internal combustion engine-driven vehicle, the thermal energy produced by the combustion process is exchanged between the ambiance, engine components, HVAC, lubrication oil, and coolant [2]. HVAC is the only module integrated into the vehicle functions to maintain the CAT set by the user, and in this article, we propose a novel methodology to predict the set CAT. It is known from the existing literature that the CAT is reduced by the ACS [3] and increased by extracting heat from the engine surface, as shown in Figure 1 [4,5].

Ref. [6] adopted an adaptive control technique to alter the functioning of the ACS based on environmental conditions and driver behaviour. This method produced simulation results that project $1 \%$ more energy-saving than the conventional fuzzy logic control used by [7]. The fuzzy logic control developed in [7] contained an iterative analysis of CAT and the ACS compressor load to evaluate the system's performance, including reduced energy consumption [7]. Ref. [8] developed an ACS to produce a desirable CAT and maintain the air quality in conjunction with the engine controller by activating cruise control. Refs. [9,10] investigated the parameters of the mass flow rate of the air by dynamically adjusting the blower speed and air-gates opening under various thermal loads, which resulted in 
reduced energy consumption. Ref. [11] developed a heat balance method for estimating the thermal load encountered by the cabin using a predictive model mapping the driving conditions. This method could potentially predict thermal comfort in real-time and thus reduce the power consumption of the ACS. Finally, Ref. [12] developed an optimised control model for three stages to enhance the efficiency of the ACS. These stages include optimising the ACS operating point based on the control inputs and relevant actuators.

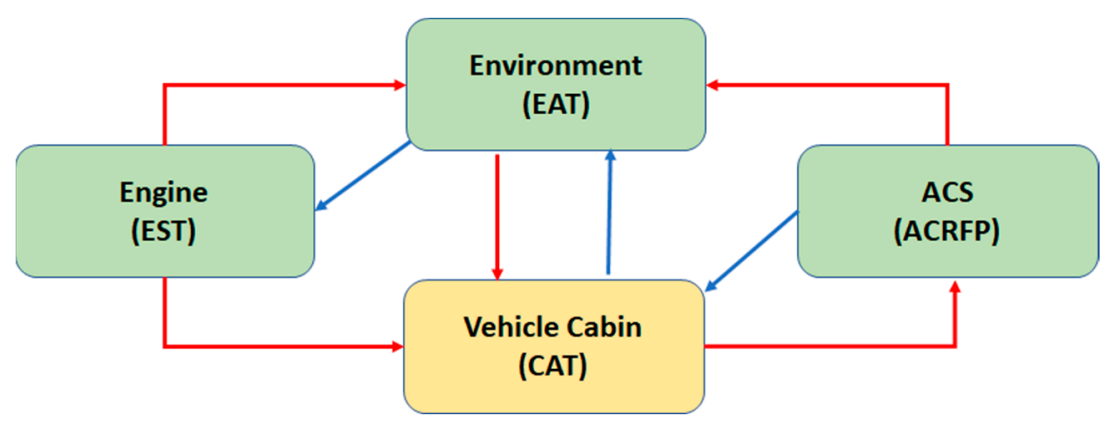

Figure 1. Heat exchange: Vehicle interactive elements.

All the models developed to optimise the HVAC system have automated functionality developed by engineers and do not involve the user's input. The user's input in real-time is defined as DBV consisting of the elements (Speeding, Steering, CAT). Ref. [13] proposed a novel methodology to predict Speed, and in this article, we propose to predict CAT utilising similar concepts. Also, none of the existing literature proposed a model that can generate a unique CAT driven by the user's command to augment the HVAC efficiency. In this article, we propose a method to predict the CAT profile in a definite range defined by the user (e.g., [65 70] ${ }^{\circ} \mathrm{F}$ or $[7075]^{\circ} \mathrm{F}$ ), analogous to [13].

Inspired by the research $[13,14]$, a similar NARX DL model was developed, mapping the elements VLV- [Odometer, DBV, EAT] and CATOP_EST and ACRFP (HVAC). CATOP is an empirical parameter defined to represent the HVAC elements, and optimal HVAC criteria are defined and applied to the predicted CATOP in real-time. We estimated a unique CAT value by the interactive analysis, and the detailed procedure adopted is shown in the following sections. The rest of the article is organised as follows: Sections 2 and 4 propose predicting CATOP and CAT, whereas Section 3 defines the optimal HVAC criteria applied to the CATOP to generate an optimal CAT profile. In Section 5, the detailed results of the predictive model and experimental techniques are presented.

\section{Predictive Model-CATOP}

We discuss the NARX DL model elements to predict CATOP-ACRFP and EST in this section.

\subsection{Modelling}

The NARX DL model is developed mapping the VLV—(Time step, Odometer, DBV, EAT) and CATOP - (EST, ACRFP) (Figure 2) with default training properties [14]. The DBV is defined with five parameters (Speed, LOT, LAT, YAR, CAT), which are the user's prerogative in real-time [15]. The parameters EAT and CAT influence thermal stress on the engine [16], whereas the odometer reading reflects the age of the vehicle. This article does not consider the remaining VLV elements (vehicle posture [17], aerodynamics, tire pressure) as their effects are assumed to be insignificant. Also, the orientation of the RRC vector is insignificant for the analysis; thus, positive values of LAT and YAR are considered in developing the DL models. The purpose of selecting EST and ACRFP as outputs and methodology to develop the DL models are discussed in Section 3 [18] and Section 5.2. 


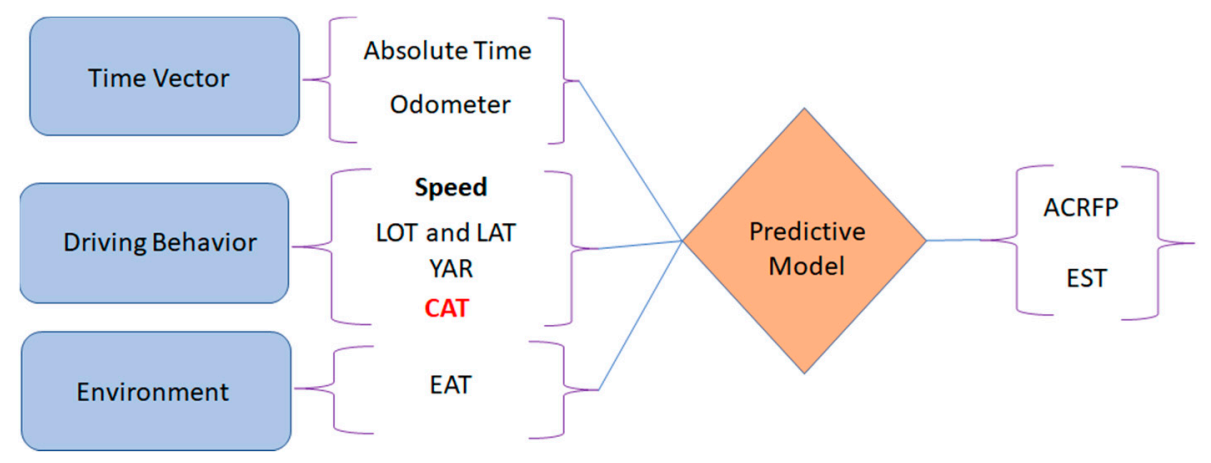

Figure 2. NARX DL Model-Inputs and Outputs [13].

\section{Optimal CATOP Criteria}

In the existing literature, researchers optimised the HVAC system by applying the constraint of fuel economy [19]. However, the experimental results reflect the fuel saved per trip being $<2 \%$, and none of the techniques had involved the parameter CAT $\left({ }^{\circ} \mathrm{F}\right)$. Deviating from the traditional concept of optimising fuel economy, based on the real-time data retrieved (Section 5.1), two parameters, EST $\left({ }^{\circ} \mathrm{F}\right)$ and ACRFP (PSI), that reflect HVAC performance were identified. EST $\left({ }^{\circ} \mathrm{F}\right)$ is maintained in a specific range to achieve optimal thermal stress on the engine by transferring heat to four main elements-engine oil, cabin, coolant/radiator, and external ambience [20].

Similarly, the ACS functionality is affected by multiple parameters, including compressor load, engine fan speed, and power consumed. However, by analysing the real-time test data (Section 5.1), we conclude that variations of these parameters were insignificant due to changes in CAT $\left({ }^{\circ} \mathrm{F}\right)$. Hence, we considered ACRFP (PSI) as the CATOP element, which showed substantial fluctuations by varying EAT $\left({ }^{\circ} \mathrm{F}\right)$ and $\mathrm{CAT}\left({ }^{\circ} \mathrm{F}\right)$.

\subsection{CATOP Element-EST}

It is known from the existing literature that optimal thermal stress on the engine components and ideal engine oil viscosity is achieved when EST $=90^{\circ} \mathrm{C}\left(194{ }^{\circ} \mathrm{F}\right)$ [21]. Hence, the conformance between the predicted EST $\left(E S T_{p}\right)$ and ideal EST $\left(E S T_{i}=90^{\circ} \mathrm{C}\right)$ must be minimal for optimal HVAC functionality. The real-time test data depict that EST $\left({ }^{\circ} \mathrm{F}\right)$ recorded was observed in the range of $[165220]^{\circ} \mathrm{F}$.

Hence, we define two empirical parameters [A1 A2] to split the scenarios representing the cases when the predicted EST $\left(E S T_{p}\right)>90{ }^{\circ} \mathrm{C}$ and $<90^{\circ} \mathrm{C}$. The parameters [A1 A2] are plotted for the snippet of the test case $(1 \mathrm{~km})$, and the area under the curve is evaluated [Area_A1, Area_A2]. Hence, the minimum value of the parameters [Area_A1, Area_A2] is considered the criteria for the element EST $\left({ }^{\circ} \mathrm{F}\right)$.

$$
\begin{gathered}
A 1=\left(E S T_{p}-E S T_{i}\right), \text { if } E S T_{p}>E S T_{i}=90^{\circ} \mathrm{C} . \\
A 1=0, \text { if } E S T_{p}<E S T_{i}=90^{\circ} \mathrm{C}=194{ }^{\circ} \mathrm{F} . \\
A 2=\left(E S T_{i}-E S T_{p}\right), \text { if } E S T_{p} \leq E S T_{i}=90^{\circ} \mathrm{C} . \\
A 2=0, \text { if } E S T_{p} \geq E S T_{i}=90^{\circ} \mathrm{C}=194^{\circ} \mathrm{F} .
\end{gathered}
$$

\subsection{CATOP Element-ACRFP}

The ACS of the test vehicle was assumed to function with the refrigerant R134a. The ideal functioning of the ACS was defined by correlating the upper boundary limits of the ACRFP for the corresponding EAT $\left({ }^{\circ} \mathrm{F}\right)$ [22]. We show these values in Figure 3 and Table S2, and the intermittent higher boundary values of ACRFP (PSI) for EAT $\left({ }^{\circ} \mathrm{F}\right)$ in the range $[65110]^{\circ} \mathrm{F}$ could be estimated by basic linear interpolation. Hence, an empirical parameter $\mathrm{B}$ (PSI) is defined, representing the conformance of the predicted $A C R F P_{p}$ and threshold 
$A C R F P_{h}$. The threshold $A C R F P_{h}$ is estimated by correlating the recorded EAT using the plot shown in Figure 3. In a generic case, this value is significant when EAT $<65^{\circ} \mathrm{F}$.

$$
\begin{gathered}
B=\left(A_{C R F P}-A C R F P_{h}\right), \text { if } A C R F P_{p}>A C R F P_{h} \\
B=0, \text { if } A C R F P_{p} \leq A C R F P_{h} \text { or EAT }<65^{\circ} \mathrm{F}
\end{gathered}
$$

Similar to the previous criteria, parameter $B$ is plotted for the test case snippet, and Area_B represents the area under curve B. Therefore, minimum Area_B was considered the optimal HVAC criteria corresponding to the element ACRFP (PSI).

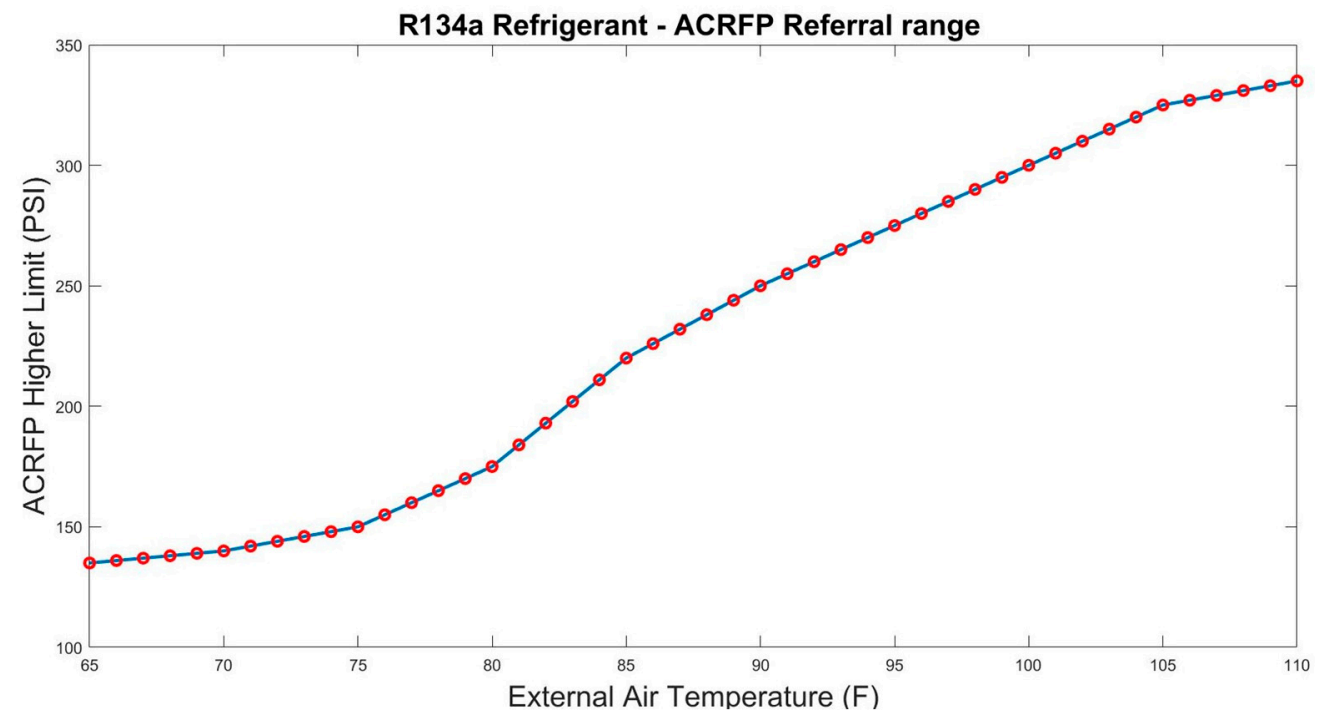

Figure 3. R134a ACS-ACRFP threshold curve.

\subsection{Smoothness Measure-EST and ACRFP}

In this research, we developed the CATOP conformance vector Area $=$ [Area_A1, Area_A2, Area_B] plots for the test case snippets 100 steps $(1 \mathrm{step}=10 \mathrm{~m})$. Along with the area under the curve, we considered the smoothness measure (S) for the plots [A1 A2 B] as the third optimal HVAC criterion. The spline fit was embedded into the curves [A1 A2 B] using the built-in functions of MATLAB [13].

$$
\mathrm{S}=\left[R^{2}, \operatorname{Adj} R^{2}, \mathrm{SSE}, \mathrm{RMSE}\right]
$$

The vector $\mathrm{S}$ represents the smoothness measure vector estimated using the traditional statistical techniques $R^{2} / \operatorname{Adj} R^{2}$ and SSE/RMSE. $R^{2}$ is a statistical measure of how close the data are to the fitted regression line, whereas Adj $R^{2}$ is a modified version of $R^{2}$ adjusted for the number of predictors in the model, which is always lower than $R^{2}$. SSE is the residual sum of squares of the conformance between the predicted and fitted curve, and the square root of the mean SSE represents RMSE. Higher values of $R^{2} / \operatorname{Adj} R^{2}$ and lower SSE/RMSE were considered a good fit for the curve [13]. $R^{2} /$ Adj $R^{2}$ values range between [0 1], representing the percentage of match, whereas SSE/RMSE have the same units of the parameters. Therefore, the vector S is estimated individually for the plots [S_A1 S_A2 S_B] by fitting a spline using the built-in toolboxes of MATLAB. The mathematical models of vector $\mathrm{S}$ are not the scope of this article.

\section{Prediction of CAT}

In this research, we challenged the constant $\mathrm{CAT}\left({ }^{\circ} \mathrm{F}\right)$ set by the user, and a novel model to predict optimal CAT profile in a definite user-defined range was developed. The default range of allowable CAT, [65 70] ${ }^{\circ} \mathrm{F}$ for EAT $>65^{\circ} \mathrm{F}$ and $[7075]^{\circ} \mathrm{F}$ for EAT $<65^{\circ} \mathrm{F}$, 
are considered. In the following sections, we estimate the optimal CAT for future steps by following the process shown in Figure 4 [13].

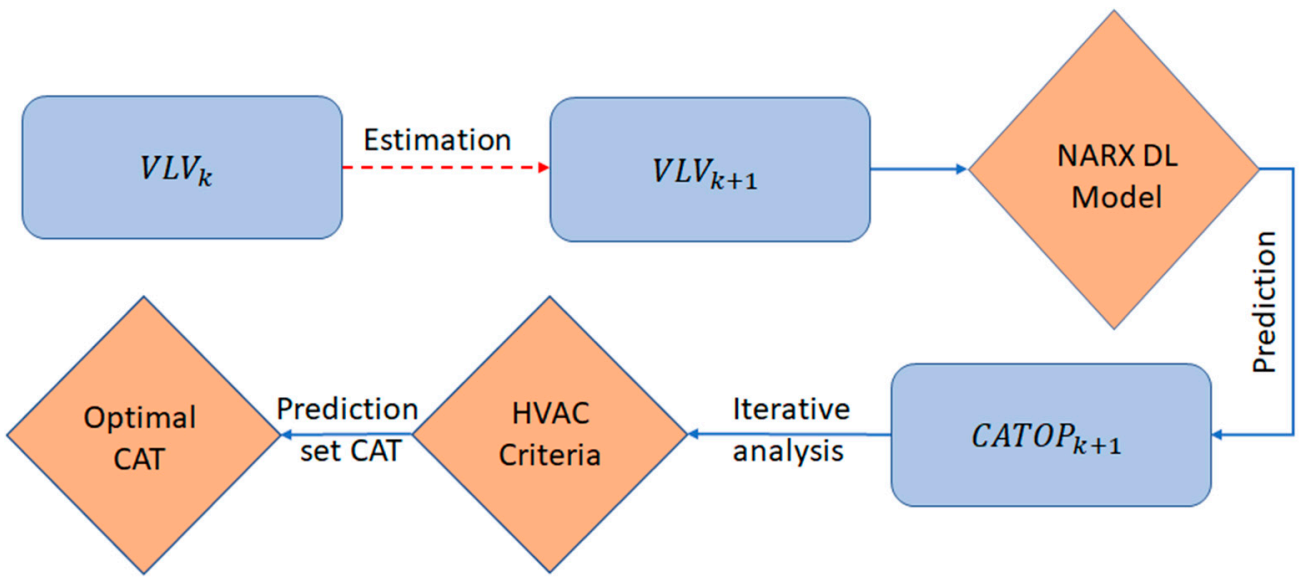

Figure 4. Prediction of CAT-Process [13].

\subsection{Estimation of Future Inputs-NARX DL Model}

Step 1: We estimated the future input states $\left(V L V_{k+1}\right)$ of the DL model relative to the vehicle's current state $\left(V L V_{k}\right)$ by the equation set shown in Table 1 . The magnitude of the odometer reading $O_{k+1}(\mathrm{~km})$ and timestep $T_{k+1}(\mathrm{~s})$ is estimated using basic interpolation, and the vehicle's speed $S_{k+1}=\mathrm{SL}(\mathrm{MPH})$ since ACCSSP $\approx \mathrm{SL}$.

Table 1. Equation Set-Prediction of future input states.

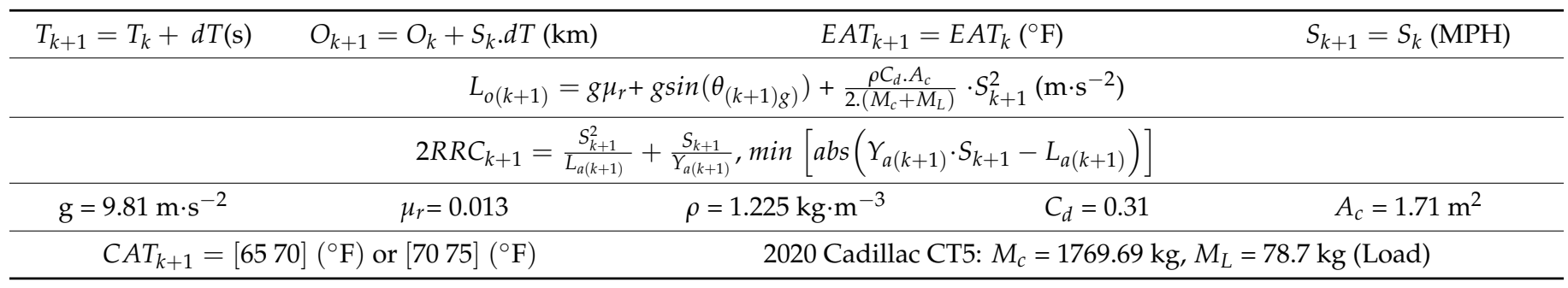

The parameters YAR $\left(Y_{a(k+1)}\right)$ and $\operatorname{LAT}\left(L_{a(k+1)}\right)$ are estimated using the equations, framed assuming ISB [23], whereas as LOT $\left(L_{o(k+1)}\right)$ is calculated based on the vehicle resistance as shown in Table 1 . The vehicle is assumed to be integrated with infotainment and connectivity features, which assist our work to retrieve the terrain parameters $\left[R R C_{k+1}\right.$, $\left.\theta_{g(k+1)}\right]$, along with $E A T_{k+1}$ based on the GPS location and infotainment maps (e.g., Super and Ultra cruise features integrated into the Cadillac vehicle segment-GMC) [13].

We varied $C A T_{k+1}\left({ }^{\circ} \mathrm{F}\right)$ in a specific default range based on $E A T_{k+1}\left({ }^{\circ} \mathrm{F}\right)$. A sample set of the future input states $\left(V L V_{k+1}\right)$ of the DL model for 100 steps are presented in Table 2.

\subsection{Prediction of Outputs-NARX DL Model}

Step 2: Six input sets $(1$ set $=1000 \mathrm{~m})$ are developed by varying the CAT in the user-defined range $[6570]^{\circ} \mathrm{F}$, based on step 1 . We fed the input sets into the NARX DL model and predicted the corresponding output sets (CATOP vectors). We adopted a similar procedure for the winter case scenario with $\mathrm{CAT}=[7075]^{\circ} \mathrm{F}$. The properties and precision of the prediction of the DL model are discussed in Section 5.2. 
Table 2. Estimation of Future Inputs_DL Model, 2020 Cadillac CT5 (100 steps = 1000 m) [13].

\begin{tabular}{ccccccccc}
\hline Step & $\begin{array}{c}\text { Odometer } \\
\mathbf{( k m})\end{array}$ & $\begin{array}{c}\text { Speed } \\
(\mathbf{M P H})\end{array}$ & $\begin{array}{c}\text { RRC } \\
\mathbf{( m )}\end{array}$ & $\begin{array}{c}\text { YAR } \\
\left(\mathbf{r a d} \cdot \mathbf{s}^{-1}\right)\end{array}$ & $\begin{array}{c}\text { LAT } \\
\left(\mathbf{m} \cdot \mathbf{s}^{-2}\right)\end{array}$ & $\begin{array}{c}\text { LOT } \\
\left(\mathbf{m} \cdot \mathbf{s}^{-2}\right)\end{array}$ & $\begin{array}{c}\text { EAT } \\
\left({ }^{\circ} \mathbf{F}\right)\end{array}$ & $\begin{array}{c}\text { CAT } \\
\left({ }^{\circ} \mathbf{F}\right)\end{array}$ \\
\hline$D_{0}$ & 15,000 & 70 & 8304.140 & 0.216 & 0.1179 & 0.4375 & $78.5,38.3$ & {$[6570],[7075]$} \\
\hline$d D_{10}$ & $15,000.1$ & 70 & 8304.140 & 0.216 & 0.1179 & 0.375 & $78.5,38.3$ & {$[6570],[7075]$} \\
\hline$d D_{20}$ & $15,000.2$ & 70 & 8304.140 & 0.216 & 0.1179 & 0.3125 & $78.5,38.3$ & {$[6570],[7075]$} \\
\hline$d D_{30}$ & $15,000.3$ & 70 & 9342.157 & 0.192 & 0.1048 & -0.125 & $78.5,38.3$ & {$[6570],[7075]$} \\
\hline$d D_{40}$ & $15,000.4$ & 70 & $24,912.42$ & 0.072 & 0.0393 & -0.1875 & $78.5,38.3$ & {$[6570],[7075]$} \\
\hline$d D_{50}$ & $15,000.5$ & 70 & $74,737.261$ & 0.024 & 0.0131 & -0.0625 & $78.5,38.3$ & {$[6570],[7075]$} \\
\hline$d D_{60}$ & $15,000.6$ & 70 & $74,737.261$ & 0.024 & 0.0131 & 0.25 & $78.5,38.3$ & {$[6570],[7075]$} \\
\hline$d D_{70}$ & $15,000.7$ & 70 & $37,368.630$ & 0.048 & 0.0262 & 0.25 & $78.5,38.3$ & {$[6570],[7075]$} \\
\hline$d D_{80}$ & $15,000.8$ & 70 & $24,912.420$ & 0.072 & 0.0393 & 0.1875 & $78.5,38.3$ & {$[6570],[7075]$} \\
\hline$d D_{90}$ & $15,000.9$ & 70 & $24,912.420$ & 0.072 & 0.0393 & 0.1875 & $78.5,38.3$ & {$[6570],[7075]$} \\
\hline$D_{100}$ & 15,001 & 70 & 9342.157 & 0.192 & 0.1048 & 0.3125 & $78.5,38.3$ & {$[6570],[7075]$} \\
\hline
\end{tabular}

\subsection{Implementation-HVAC Criteria}

Step 3: We determined the corresponding CATOP conformance vector [A1 A2 B] by analysing the predicted output sets. The optimal HVAC criteria were applied, and we estimated the performance vector [Area, $R^{2}$, Adj $R^{2}$, SSE, RMSE] for every set of outputs (Table 3). Based on these values, we identified the top three CAT values, satisfying the CATOP criteria for $100 \mathrm{~m}$ shown in Table 4. Therefore, we framed the CAT matrix for $1000 \mathrm{~m}$ for two scenarios, as shown in Table 5 .

Table 3. Iterative Analysis-DL Model, 2020 Cadillac CT5 (10 steps = 100 m) [13].

\begin{tabular}{|c|c|c|c|c|c|c|c|c|c|c|c|c|c|c|c|}
\hline \multirow{2}{*}{$\frac{\text { CAT }}{{ }^{\circ} \mathbf{F}}$} & \multicolumn{5}{|c|}{ A1 } & \multicolumn{5}{|c|}{ A2 } & \multicolumn{5}{|c|}{ B } \\
\hline & Area & $\mathbf{R}$ & $\operatorname{Adj} R^{2}$ & SSE & RMSE & Area & $\mathbf{R}$ & $\operatorname{Adj} R^{2}$ & SSE & RMSE & Area & $\mathbf{R}$ & $\operatorname{Adj} R^{2}$ & SSE & RMSE \\
\hline \multicolumn{16}{|c|}{ ACCSSP $=70 \mathrm{MPH} ; \mathrm{EAT}=78.75^{\circ} \mathrm{F}$} \\
\hline 65 & 114.5 & 0.994 & 0.986 & 1.495 & 0.194 & 1931 & 0.998 & 0.994 & 61.03 & 1.242 & 2252 & 0.995 & 0.989 & 158.9 & 2.004 \\
\hline 66 & 175.2 & 0.995 & 0.987 & 2.749 & 0.264 & 1994 & 0.998 & 0.994 & 64.36 & 1.275 & 2365 & 0.996 & 0.989 & 167.8 & 2.059 \\
\hline 67 & 216.5 & 0.992 & 0.979 & 6.555 & 0.407 & 2020 & 0.998 & 0.994 & 67.47 & 1.306 & 2379 & 0.996 & 0.990 & 149.4 & 1.943 \\
\hline 68 & 203.8 & 0.992 & 0.981 & 5.391 & 0.369 & 1872 & 0.997 & 0.993 & 67.63 & 1.307 & 2399 & 0.996 & 0.990 & 155.5 & 1.983 \\
\hline 69 & 178.2 & 0.993 & 0.982 & 3.933 & 0.315 & 1688 & 0.997 & 0.993 & 52.16 & 1.148 & 2402 & 0.996 & 0.990 & 167.6 & 2.058 \\
\hline 70 & 201.9 & 0.995 & 0.986 & 3.773 & 0.309 & 1612 & 0.998 & 0.994 & 44.56 & 1.061 & 2416 & 0.996 & 0.990 & 162.6 & 2.027 \\
\hline \multicolumn{16}{|c|}{$\mathrm{ACCSSP}=70 \mathrm{MPH} ; \mathrm{EAT}=38.3^{\circ} \mathrm{F}$} \\
\hline 70 & 47.069 & 0.990 & 0.976 & 0.551 & 0.118 & 40.095 & 0.987 & 0.968 & 0.938 & 0.154 & 0.000 & 0.000 & 0.000 & 0.000 & 0.000 \\
\hline 71 & 45.876 & 0.990 & 0.975 & 0.557 & 0.119 & 40.662 & 0.987 & 0.968 & 0.961 & 0.156 & 0.000 & 0.000 & 0.000 & 0.000 & 0.000 \\
\hline 72 & 45.408 & 0.990 & 0.975 & 0.561 & 0.119 & 41.013 & 0.987 & 0.968 & 0.978 & 0.157 & 0.000 & 0.000 & 0.000 & 0.000 & 0.000 \\
\hline 73 & 45.575 & 0.990 & 0.975 & 0.566 & 0.120 & 41.169 & 0.987 & 0.968 & 0.988 & 0.158 & 0.000 & 0.000 & 0.000 & 0.000 & 0.000 \\
\hline 74 & 46.270 & 0.990 & 0.975 & 0.569 & 0.120 & 41.162 & 0.987 & 0.968 & 0.993 & 0.158 & 0.000 & 0.000 & 0.000 & 0.000 & 0.000 \\
\hline 75 & 47.368 & 0.990 & 0.975 & 0.572 & 0.120 & 41.026 & 0.987 & 0.967 & 0.993 & 0.158 & 0.000 & 0.000 & 0.000 & 0.000 & 0.000 \\
\hline
\end{tabular}


Table 4. Eligible CAT Values: Iterative Analysis-Optimal CATOP. (10 steps $=100 \mathrm{~m})$.

\begin{tabular}{|c|c|c|c|c|c|c|c|c|c|c|c|c|c|c|}
\hline \multicolumn{5}{|c|}{ A1 } & \multicolumn{5}{|c|}{ A2 } & \multicolumn{5}{|c|}{ B } \\
\hline Area & $\mathbf{R}$ & $\operatorname{Adj} R^{2}$ & SSE & RMSE & Area & $\mathbf{R}$ & Adj $R^{2}$ & SSE & RMSE & Area & $\mathrm{R}$ & $\operatorname{Adj} R^{2}$ & SSE & RMSE \\
\hline \multicolumn{15}{|c|}{$\mathrm{ACCSSP}=70 \mathrm{MPH} ; \mathrm{EAT}=78.75^{\circ} \mathrm{F}$} \\
\hline 65 & 66 & 66 & 65 & 65 & 70 & 66 & 66 & 70 & 70 & 70 & 67 & 67 & 67 & 67 \\
\hline 66 & 70 & 70 & 66 & 66 & 69 & 65 & 65 & 69 & 69 & 69 & 68 & 68 & 68 & 68 \\
\hline 69 & 65 & 65 & 70 & 70 & 68 & 67 & 67 & 65 & 65 & 68 & 70 & 70 & 65 & 65 \\
\hline \multicolumn{15}{|c|}{$\mathrm{ACCSSP}=70 \mathrm{MPH} ; \mathrm{EAT}=38.3^{\circ} \mathrm{F}$} \\
\hline 72 & 70 & 70 & 70 & 70 & 70 & 71 & 71 & 70 & 70 & 70 & 70 & 70 & 70 & 70 \\
\hline 73 & 71 & 71 & 71 & 71 & 71 & 70 & 70 & 71 & 71 & 71 & 71 & 71 & 71 & 71 \\
\hline 71 & 72 & 72 & 72 & 72 & 72 & 72 & 72 & 72 & 72 & 72 & 72 & 72 & 72 & 72 \\
\hline
\end{tabular}

Table 5. ACCSSP = 70 MPH: Optimal CAT Matrix- $(100$ steps $=1 \mathrm{~km})$.

\begin{tabular}{|c|c|c|c|c|c|c|c|c|c|c|c|c|c|c|c|c|c|c|c|}
\hline \multicolumn{20}{|c|}{ CAT Matrix } \\
\hline \multicolumn{10}{|c|}{$\mathrm{EAT}=78.75\left({ }^{\circ} \mathrm{F}\right)$} & \multicolumn{10}{|c|}{$\mathrm{EAT}=38.3\left({ }^{\circ} \mathrm{F}\right)$} \\
\hline$d T_{1}$ & $d T_{2}$ & $d T_{3}$ & $\mathrm{~d} T_{4}$ & $\mathrm{~d} T_{5}$ & $d T_{6}$ & $d T_{7}$ & $d T_{8}$ & $d T_{9}$ & $d T_{10}$ & $d T_{1}$ & $d T_{2}$ & $d T_{3}$ & $\mathrm{~d}_{4}$ & $\mathrm{~d} T_{5}$ & $d T_{6}$ & $d T_{7}$ & $d T_{8}$ & $d T_{9}$ & $d T_{10}$ \\
\hline 66 & 66 & 66 & 68 & 68 & 65 & 66 & 66 & 68 & 66 & 70 & 70 & 70 & 70 & 70 & 70 & 72 & 70 & 71 & 73 \\
\hline 67 & 67 & 67 & 66 & 69 & 66 & 67 & 67 & 66 & 67 & 71 & 71 & 71 & 71 & 71 & 71 & 70 & 71 & 72 & 74 \\
\hline 65 & 65 & 65 & 67 & 70 & 67 & 65 & 65 & 67 & 65 & 72 & 72 & 72 & 72 & 72 & 72 & 71 & 72 & 70 & 75 \\
\hline
\end{tabular}

\subsection{Estimation of Optimal CAT}

Step 4: The CAT matrix $(3 \times 10)$ results in a maximum of $3^{10}$ possible CAT profiles for $1000 \mathrm{~m}$. In the final step, we proposed the following algorithm to identify the unique CAT profile [13].

Algorithm to Estimate CAT

1. Assuming the set CAT at step $\mathrm{k}$ was $C_{k}$, if the eligible CAT's were either $C_{k}+1, C_{k}$, or $C_{k}-1$, then the highest magnitude among the three was selected as $C_{k+1}$, for the case $E A T_{k} \geq 65^{\circ} \mathrm{F}$ and selected the lower value as $C_{k+1}$ for the case $E A T_{k}<65^{\circ} \mathrm{F}$.

2. We chose the value of $C_{k+1}$ closer to $C_{k}$. If this resulted in two values, the higher value was considered $C_{k+1}$ for the case $E A T_{k} \geq 65^{\circ} \mathrm{F}$, and the lower value for the case $E A T_{k}<65^{\circ} \mathrm{F}$.

3. If the eligible CATs were neither $C_{k}+1, C_{k}$ nor $C_{k}-1$, then $C_{k+1}=C_{k}$.

4. If $C_{k+1}=C_{k}$ for more than 1 E3 steps $(1$ step $=10 \mathrm{~m})$, then $C_{k+1}=C_{k}+1$ for the case $E A T_{k} \geq 65^{\circ} \mathrm{F}$ or $C_{k}-1$ for $E A T_{k}<65^{\circ} \mathrm{F}$.

\section{Computational Analysis-Results}

\subsection{Data Retrieval}

We conducted this research by obtaining a 2020 Cadillac CT5 test vehicle from GMC. A two-step procedure was employed to retrieve the data from the vehicle CAN bus [24]. As a first step, we connected the hardware neoVI to the vehicle and performed the data retrieval using the software Vehicle Spy [25]. This tool records data in real-time with a frequency of $10 \mathrm{~Hz}$ (100 data points for $1 \mathrm{~s}$ ) and allows the user to retrieve the selective signal data for analysis. We performed the real-time test procedure in the second step by activating the ACC feature, which enhances EOC [26]. The speed data were collected assuming a no-slip scenario, that is, traction produced is proportional to the friction coefficient and normal forces [27]. 
Although the data were collected for every $10 \mathrm{~ms}$, substantial variations in the parameters [EST, ACRFP] were shown at a frequency of $10 \mathrm{~m}$ (odometer reading). Hence, the prediction of CAT was made with a step size of $300 \mathrm{~ms}(\sim 10 \mathrm{~m})$, and we developed the test cases by driving the vehicle for two scenarios, EAT $>65^{\circ} \mathrm{F}$ (summer) and EAT $<45^{\circ} \mathrm{F}$ (winter). We adopted these two cases on selected road segments with a range of ACCSSP $=$ [25 85] MPH, as shown in Figure 5, and the properties of the datasets (mean, StdDev, variance) of all the parameters retrieved are shown in Table 6.

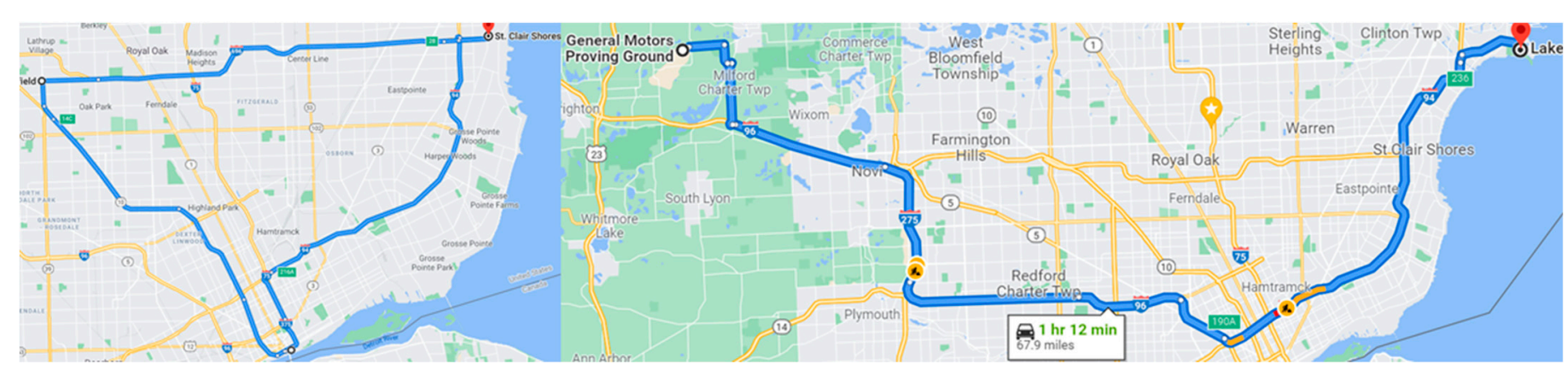

Figure 5. Path traversed-2020 Cadillac CT5 [Source: Google maps].

Table 6. Dataset sets-Real-time testing: 2020 Cadillac CT5.

\begin{tabular}{|c|c|c|c|c|c|c|}
\hline \multicolumn{7}{|c|}{ Dataset 1-Summer Data (Date: 16 June 2020) } \\
\hline Parameters & \multicolumn{3}{|c|}{ ACC Speed [25 55] MPH } & \multicolumn{3}{|c|}{ ACC Speed [55 85] MPH } \\
\hline Inputs & Mean & StdDev & Variance & Mean & StdDev & Variance \\
\hline Odometer $(\mathrm{km})$ & $16,047.528$ & 36.052 & 0.002 & $14,774.200$ & 707.602 & 0.048 \\
\hline Speed (MPH) & 39.342 & 8.948 & 0.227 & 64.739 & 6.843 & 0.106 \\
\hline LOT $\left(\mathrm{m} \cdot \mathrm{s}^{-2}\right)$ & 0.332 & 0.529 & 1.591 & -0.172 & 0.383 & -2.234 \\
\hline $\operatorname{LAT}\left(\mathrm{m} \cdot \mathrm{s}^{-2}\right)$ & 0.457 & 0.523 & 1.145 & 0.249 & 0.320 & 1.284 \\
\hline YAR $\left(\mathrm{deg} \cdot \mathrm{s}^{-1}\right)$ & 0.018 & 0.036 & 1.998 & -0.067 & 0.726 & -10.784 \\
\hline EAT $\left({ }^{\circ} \mathrm{F}\right)$ & 71.585 & 1.929 & 0.027 & 80.142 & 5.118 & 0.064 \\
\hline $\mathrm{CAT}\left({ }^{\circ} \mathrm{F}\right)$ & 82.800 & 4.856 & 0.059 & 66.922 & 1.719 & 0.026 \\
\hline Outputs & Mean & StdDev & Variance & Mean & StdDev & Variance \\
\hline $\mathrm{EST}\left({ }^{\circ} \mathrm{F}\right)$ & 198.931 & 2.649 & 0.013 & 195.183 & 17.056 & 0.087 \\
\hline ACRFP (PSI) & 160.584 & 22.056 & 0.137 & 165.131 & 21.673 & 0.131 \\
\hline \multicolumn{7}{|c|}{ Dataset 2-Winter Data (Date: 25 February 2021) } \\
\hline Parameters & \multicolumn{3}{|c|}{ ACC Speed [25 55] MPH } & \multicolumn{3}{|c|}{ ACC Speed [55 85] MPH } \\
\hline Inputs & Mean & StdDev & Variance & Mean & StdDev & Variance \\
\hline Odometer (km) & $24,875.333$ & 10.030 & 0.000 & $24,785.630$ & 5.258 & 0.000 \\
\hline Speed (MPH) & 42.973 & 7.216 & 0.168 & 68.626 & 6.253 & 0.091 \\
\hline $\mathrm{LOT}\left(\mathrm{m} \cdot \mathrm{s}^{-2}\right)$ & -0.165 & 0.443 & -2.677 & -0.158 & 0.158 & -1.000 \\
\hline $\operatorname{LAT}\left(\mathrm{m} \cdot \mathrm{s}^{-2}\right)$ & 0.159 & 0.252 & 1.581 & 0.066 & 0.193 & 2.910 \\
\hline YAR $\left(\mathrm{deg} \cdot \mathrm{s}^{-1}\right)$ & -0.114 & 0.397 & -3.492 & -0.083 & 0.285 & -3.443 \\
\hline EAT $\left({ }^{\circ} \mathrm{F}\right)$ & 39.849 & 0.870 & 0.022 & 36.383 & 0.914 & 0.025 \\
\hline $\mathrm{CAT}\left({ }^{\circ} \mathrm{F}\right)$ & 74.436 & 7.293 & 0.098 & 77.420 & 5.449 & 0.070 \\
\hline Outputs & Mean & StdDev & Variance & Mean & StdDev & Variance \\
\hline $\mathrm{EST}\left({ }^{\circ} \mathrm{F}\right)$ & 201.779 & 3.994 & 0.020 & 201.033 & 4.350 & 0.022 \\
\hline ACRFP (PSI) & 47.309 & 3.417 & 0.072 & 40.335 & 0.684 & 0.017 \\
\hline
\end{tabular}




\subsection{NARX DL Model-Prediction of CATOP}

The time-dependent data were retrieved from the 2020 Cadillac CT5 test vehicle in real-time. Therefore, among many DL models, it is known from the existing literature that only three techniques, NARX, LSTM, and ARIMA models, are widely used for time series prediction. We had tested the datasets in Ref. [13] using these techniques and concluded that the NARX DL model outperformed LSTM and ARIMA.

The NARX DL model is the simplest among all techniques, considering previous states (e.g., last three states) to predict the future state. This model is the linear representation of the dynamic system in discrete time with exogenous inputs. In Section 2.1, we proposed a novel set of inputs (VLV) and outputs (CATOP) to develop the DL model using the methodology described in Section 5.1. The NARX model is developed using the datasets retrieved from real-time testing, whose properties are shown in Table 6.

In Ref. [13], we proved the performance of the NARX method with default training properties built-in MATLAB, whose properties are defined in Table S1. In this project, we focus our attention on presenting the concept of predicting CAT profile, and developing detailed mathematical models is not the scope of our project. Our sponsors provided the software, and we used the relevant toolboxes in MATLAB to generate the training functions.

The test cases with ACCSSP $>25 \mathrm{MPH}$ were selected, and individual training networks were developed for the two CATOP-elements. The results are shown in Figures S1-S5 for EAT $>65^{\circ} \mathrm{F}$ and Figures S6-S10 for EAT $<45^{\circ} \mathrm{F}$ for ACCSSP $=[3575] \mathrm{MPH}$. Each figure consists of two parts, EST (left) and ACRFP (right). Furthermore, each plot compares the measured data (blue) with the predicted values (orange). Finally, we validated the DL model using the statistical measures (RMSE, FOD, SNR) by comparing the actual and predicted values of CATOP, reported in Table 7. The following Figures 6 and 7 depict an example of a prediction of CATOP vector for the snippet ACCSSP $=70 \mathrm{MPH}$.

Table 7. NARX Model Performance-ACC Speeds [35 75] MPH.

\begin{tabular}{|c|c|c|c|c|c|c|c|c|}
\hline \multirow{2}{*}{\multicolumn{3}{|c|}{ (Date: 16 June 2020) }} & \multicolumn{6}{|c|}{ Data Set 1: NARX—DL Model Validation (Predicted-Actual) } \\
\hline & & & \multicolumn{3}{|c|}{ EST $\left({ }^{\circ} \mathbf{F}\right)$} & \multicolumn{3}{|c|}{ ACRFP (PSI) } \\
\hline $\operatorname{ACCSSP}(\mathrm{MPH})$ & $\mathrm{CAT}\left({ }^{\circ} \mathrm{F}\right)$ & $\mathrm{EAT}\left({ }^{\circ} \mathrm{F}\right)$ & RMSE & FOD & SNR & RMSE & FOD & SNR \\
\hline 35 & 66 & 83.309 & 2.2057 & 1.5868 & 5.1067 & 14.0017 & 10.5611 & 16.1348 \\
\hline 45 & 65 & 80.375 & 1.8169 & 1.4288 & 7.1183 & 10.8150 & 7.4388 & 12.1116 \\
\hline 55 & 68 & 82.526 & 1.4794 & 1.0503 & 5.2231 & 9.5438 & 7.2012 & 20.3788 \\
\hline 65 & 67 & 81.32 & 1.66 & 1.2953 & 12.7934 & 3.7248 & 2.7151 & 6.9461 \\
\hline 75 & 70 & 86.081 & 1.2763 & 0.7945 & 5.7699 & 8.6413 & 5.2471 & 28.3001 \\
\hline \multirow{2}{*}{\multicolumn{3}{|c|}{ (Date: 25 February 2021) }} & \multicolumn{6}{|c|}{ Data Set 2: NARX_DL Model Validation (Predicted-Actual) } \\
\hline & & & \multicolumn{3}{|c|}{ EST $\left({ }^{\circ} \mathrm{F}\right)$} & \multicolumn{3}{|c|}{ ACRFP (PSI) } \\
\hline $\operatorname{ACCSSP}(\mathrm{MPH})$ & $\mathrm{CAT}\left({ }^{\circ} \mathrm{F}\right)$ & $\operatorname{EAT}\left({ }^{\circ} \mathrm{F}\right)$ & RMSE & FOD & SNR & RMSE & FOD & SNR \\
\hline 35 & 76 & 36.374 & 0.9528 & 0.6636 & 3.4284 & 2.9186 & 0.9376 & 1.3323 \\
\hline 45 & 71 & 39.047 & 0.5678 & 0.3981 & 6.2342 & 0.0281 & 0.0148 & 1.7795 \\
\hline 55 & 73 & 33.8 & 0.3916 & 0.2618 & 5.4806 & 0.0040 & 0.0007 & 0.3951 \\
\hline 65 & 74 & 37.4 & 0.3080 & 0.2158 & 15.4239 & 0.0013 & 0.0007 & 1.3281 \\
\hline 75 & 75 & 37.4 & 0.4556 & 0.3179 & 32.7227 & 0.0011 & 0.000 & 0.000 \\
\hline
\end{tabular}



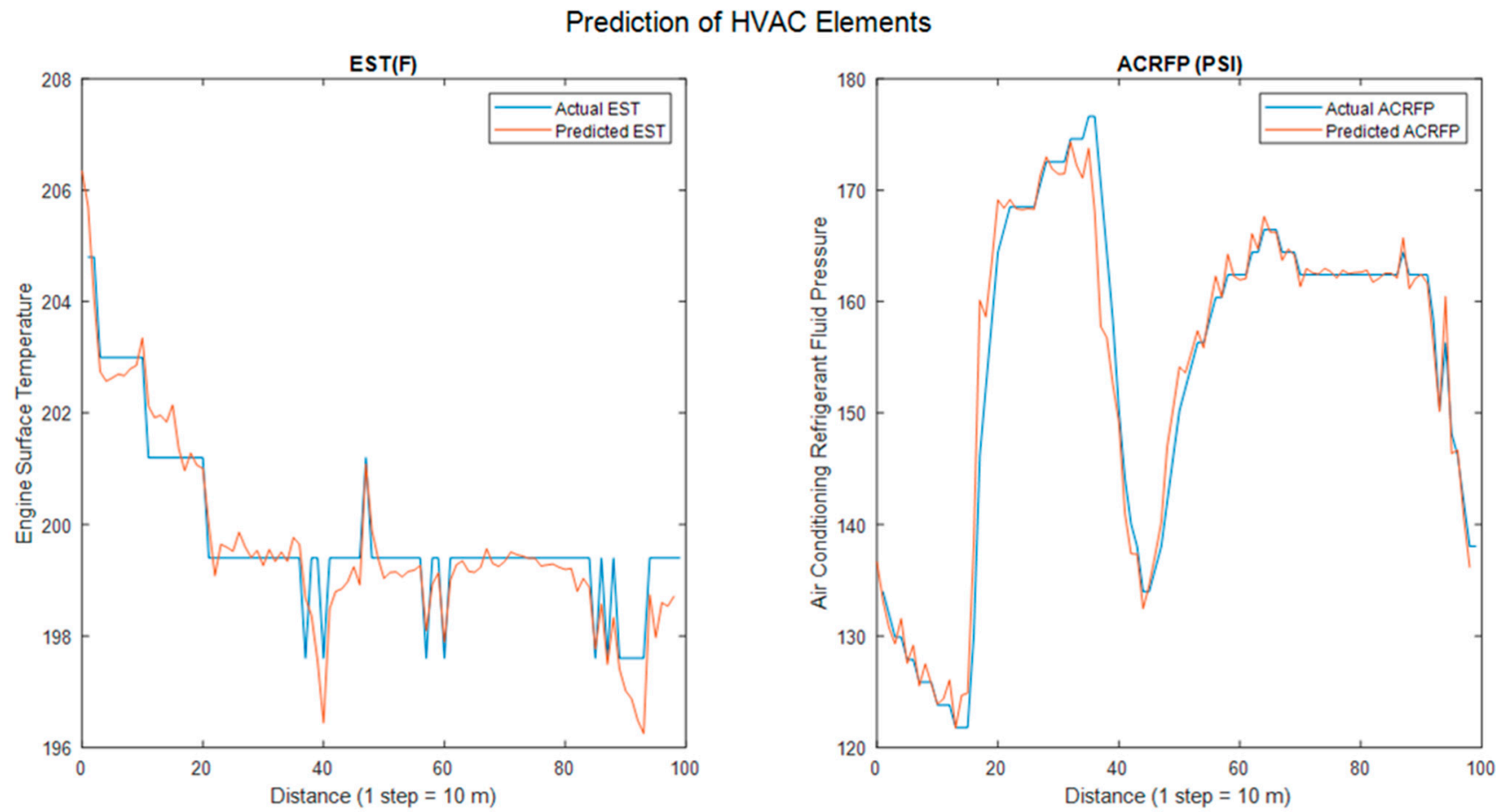

Figure 6. Prediction of CATOP-ACCSSP $=70 \mathrm{MPH} ; \mathrm{CAT}=68^{\circ} \mathrm{F} ; \mathrm{EAT}=78.75^{\circ} \mathrm{F}$.
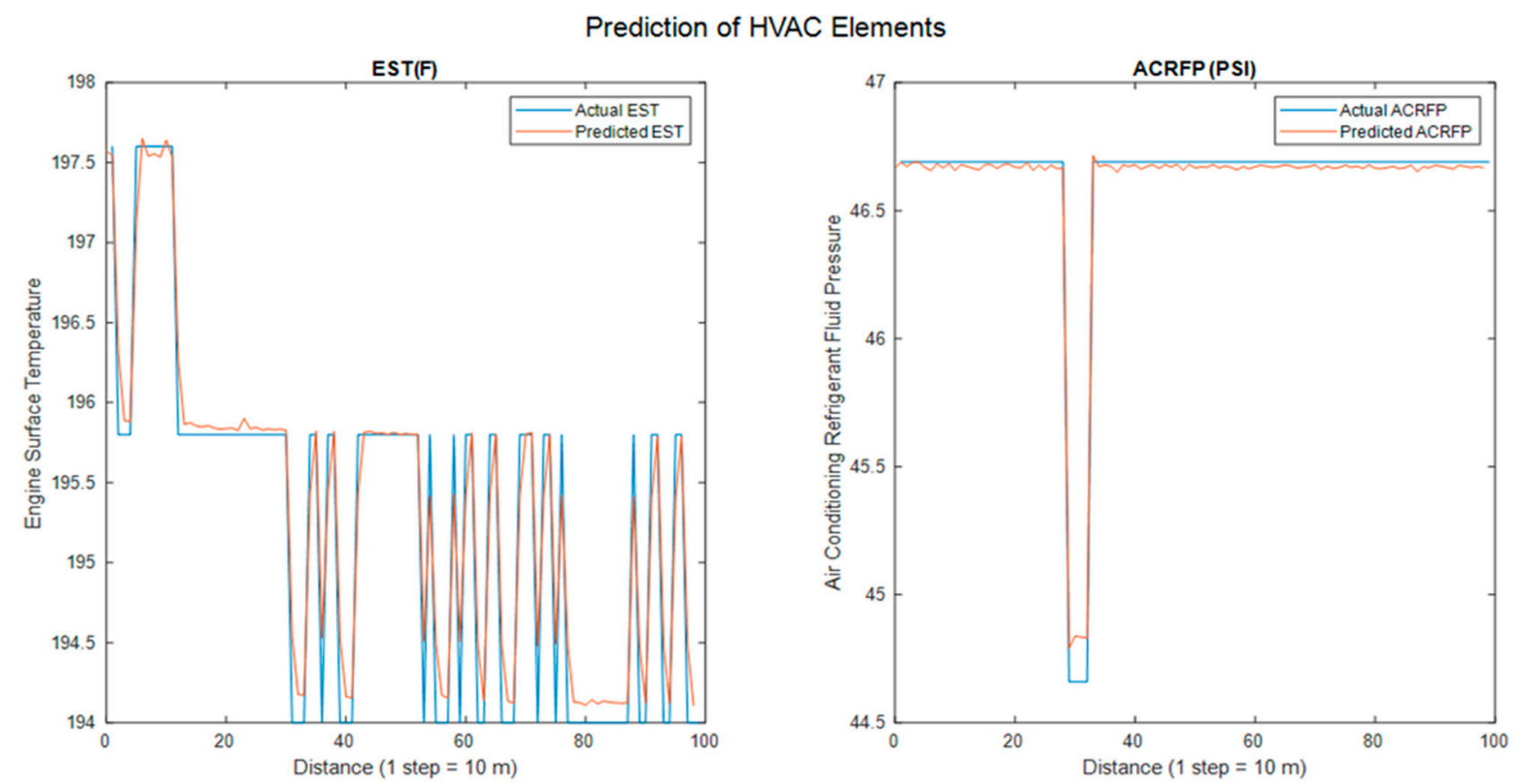

Figure 7. Prediction of $\mathrm{CATOP}-\mathrm{ACCSSP}=70 \mathrm{MPH} ; \mathrm{CAT}=72^{\circ} \mathrm{F} ; \mathrm{EAT}=40.1^{\circ} \mathrm{F}$.

\subsection{Estimation of CAT}

The analysis is conducted on the datasets retrieved using steps mentioned in Section 4. The snippet with ACCSSP $=70 \mathrm{MPH}$, with EAT $=78.75^{\circ} \mathrm{F}$ and EAT $=38.3^{\circ} \mathrm{F}$, is applied with Steps 1-3, and the results are shown in Tables 2-5. We varied the range of initial CAT with the default values, and Figures 8 and 9 depict the possible CAT profiles resulting from Step 4. Therefore, constant initial CAT $=65^{\circ} \mathrm{F}$ and $70^{\circ} \mathrm{F}$ results in unique CAT profiles shown in Figures 10 and 11. Similarly, the performance analysis for the test cases is shown in Table 8, and the plots of the CAT profiles are shown in Figures S11-S20. 


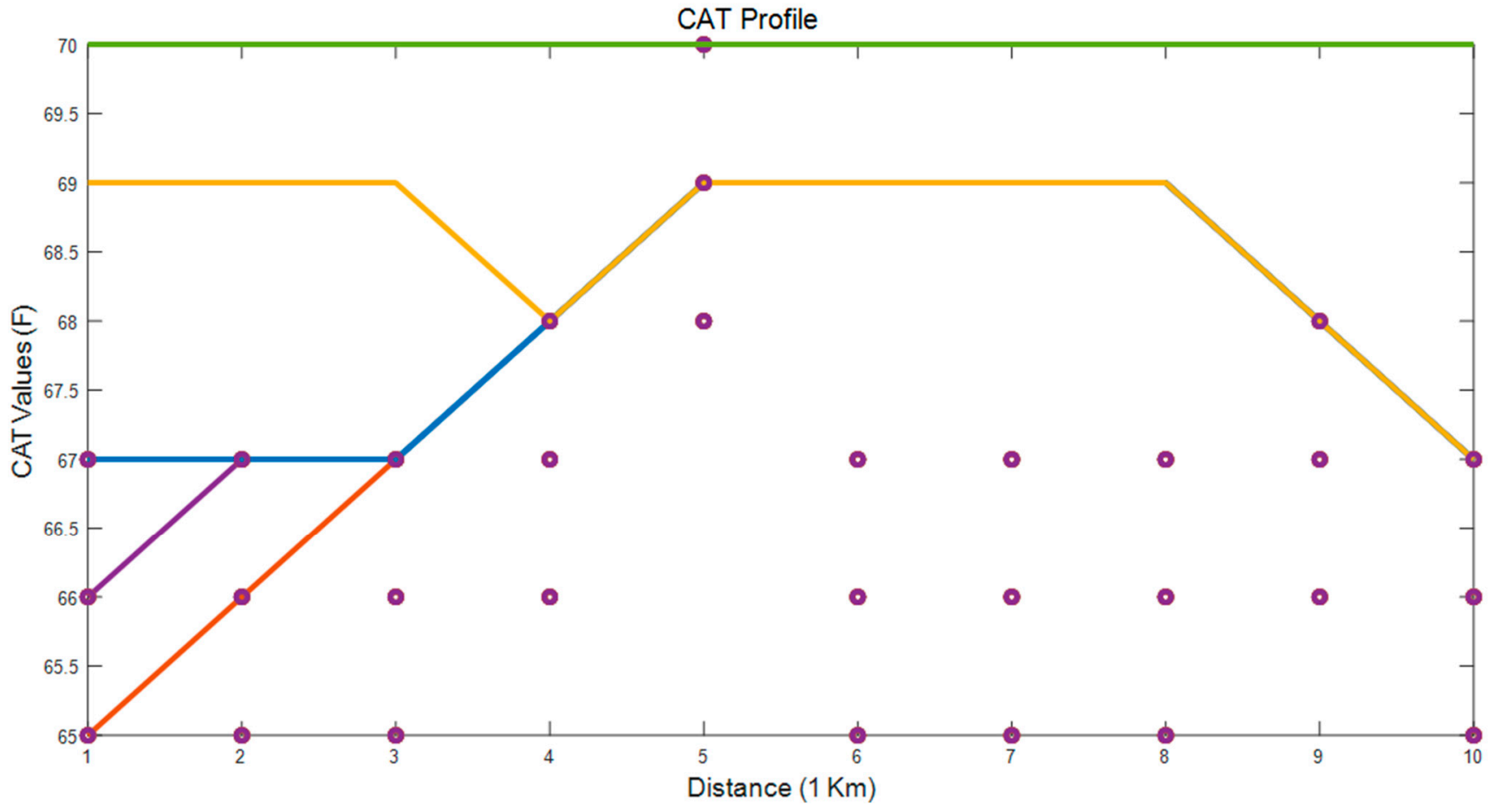

Figure 8. $\mathrm{ACCSSP}=70 \mathrm{MPH} ; \mathrm{CAT}=[6570]^{\circ} \mathrm{F} ; \mathrm{EAT}=78.75^{\circ} \mathrm{F}$.

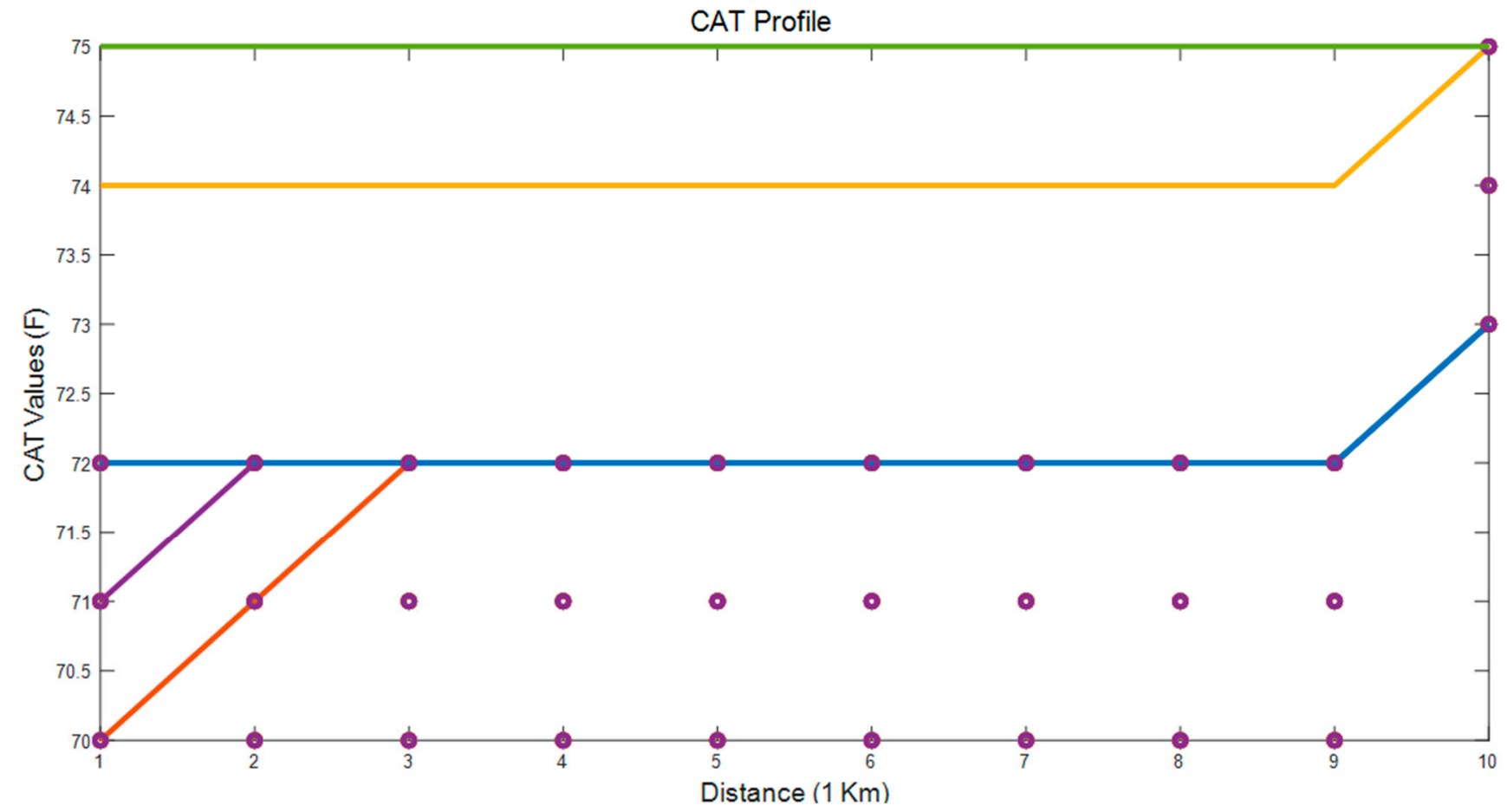

Figure 9. $\mathrm{ACCSSP}=70 \mathrm{MPH} ; \mathrm{CAT}=[7075]^{\circ} \mathrm{F} ; \mathrm{EAT}=38.3^{\circ} \mathrm{F}$. 


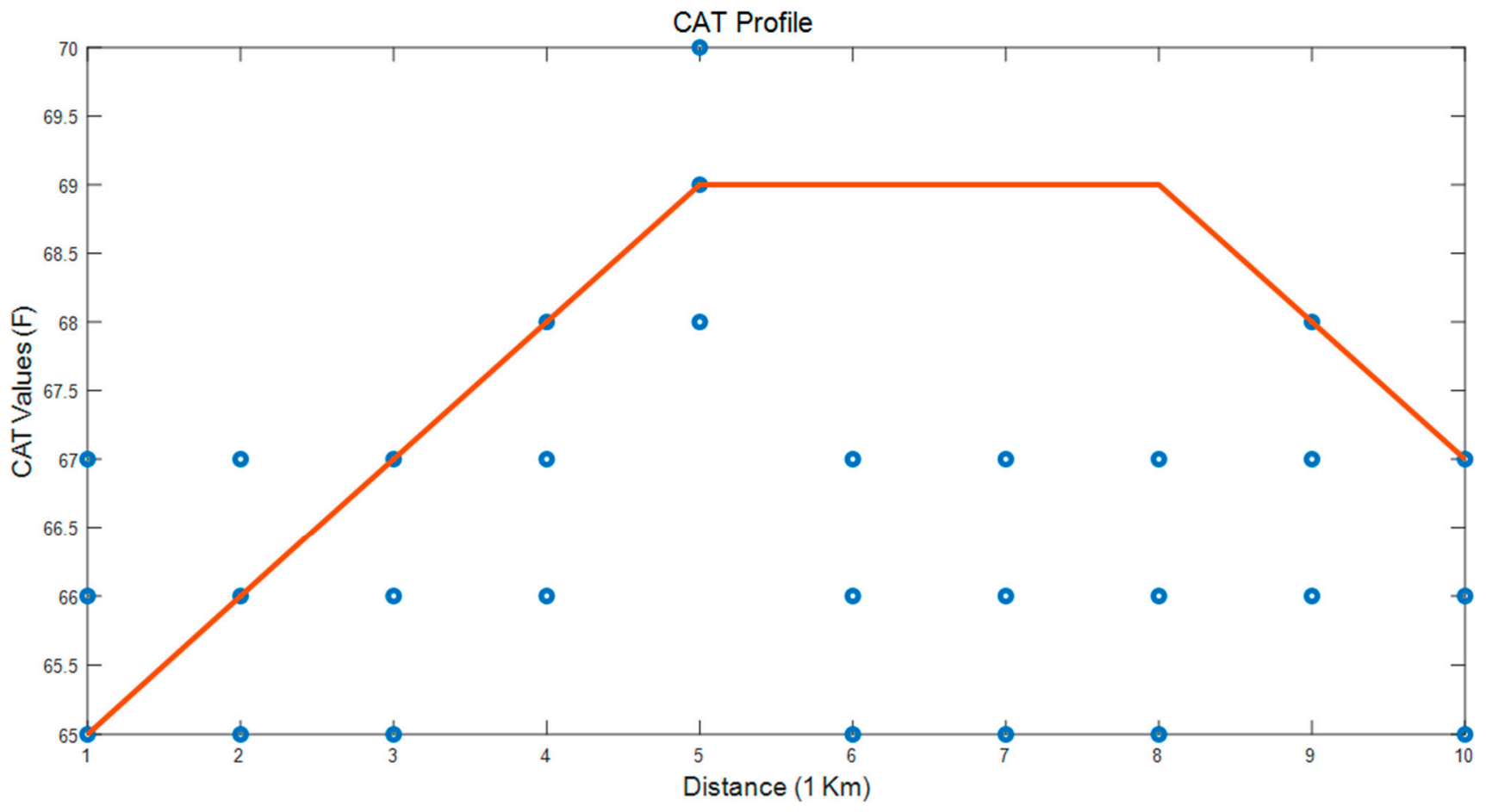

Figure 10. $\mathrm{ACCSSP}=70 \mathrm{MPH}$; Initial $\mathrm{CAT}=65^{\circ} \mathrm{F} ; \mathrm{EAT}=78.75^{\circ} \mathrm{F}$.

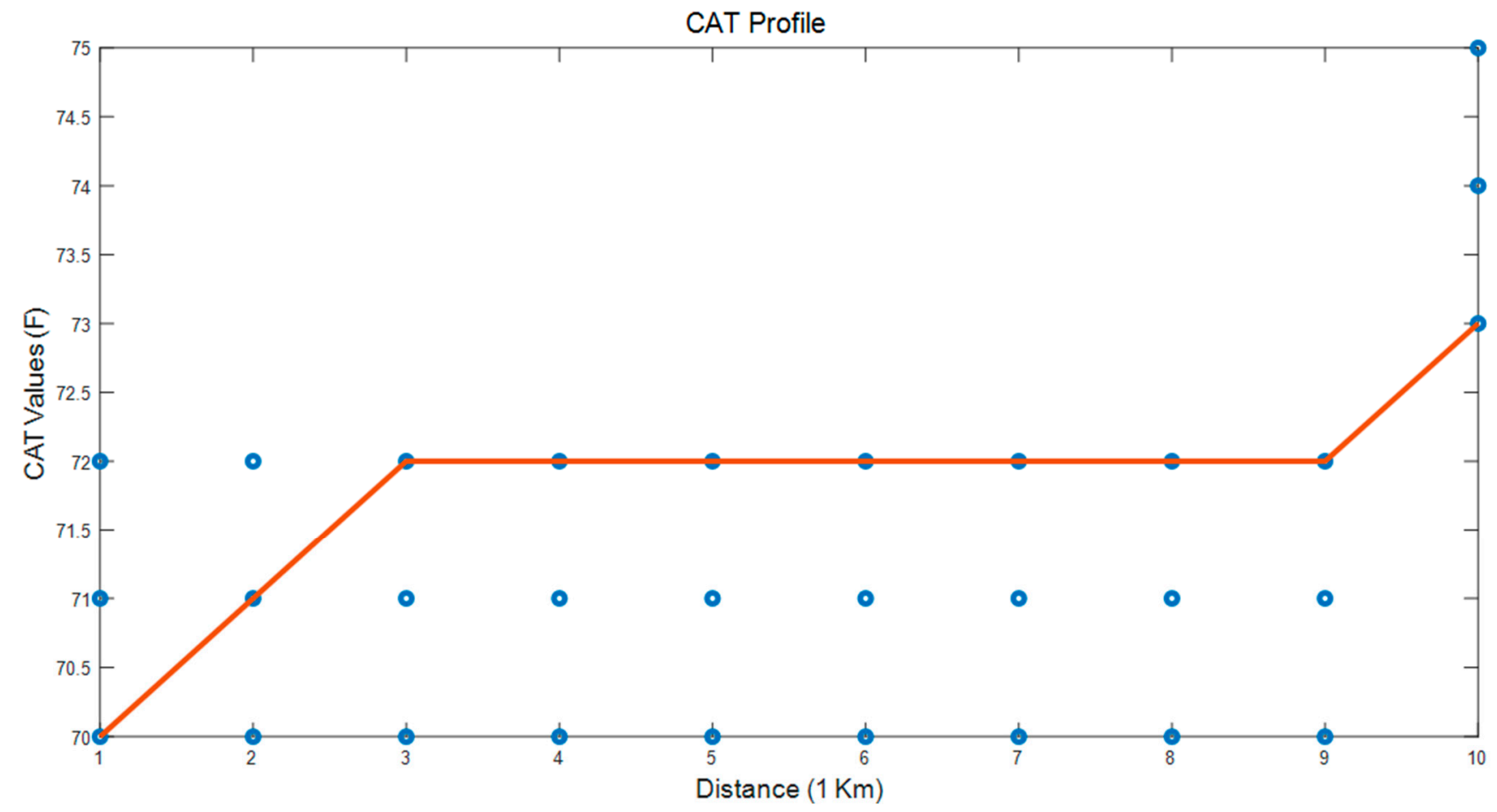

Figure 11. $\mathrm{ACCSSP}=70 \mathrm{MPH}$; Initial CAT $=70^{\circ} \mathrm{F} ; \mathrm{EAT}=38.3^{\circ} \mathrm{F}$. 
Table 8. Performance analysis-Prediction of CAT.

\begin{tabular}{|c|c|c|c|c|c|c|c|c|}
\hline Parameter & $\operatorname{EAT}\left({ }^{\circ} \mathbf{F}\right)$ & CAT Profile $\left({ }^{\circ} \mathrm{F}\right)$ & Area & Conformance & $R^{2}$ & $\operatorname{Adj} R^{2}$ & SSE & RMSE \\
\hline \multicolumn{9}{|c|}{ ACCSSP $=35 \mathrm{MPH}$} \\
\hline \multirow{4}{*}{$\begin{array}{c}\text { EST } \\
{[\mathrm{A} 1, \mathrm{~A} 2]}\end{array}$} & \multirow{2}{*}{78.566} & 66 & 515.975 & \multirow{2}{*}{-9.312} & 0.960 & 0.900 & 2.981 & 0.276 \\
\hline & & Predicted & 506.662 & & 0.810 & 0.526 & 22.762 & 0.762 \\
\hline & \multirow{2}{*}{36.806} & 74 & 424.360 & \multirow{2}{*}{4.411} & 0.989 & 0.973 & 12.604 & 0.567 \\
\hline & & Predicted & 428.771 & & 0.992 & 0.980 & 11.889 & 0.551 \\
\hline \multirow{4}{*}{$\begin{array}{c}\text { ACRFP } \\
\text { (B) }\end{array}$} & \multirow{2}{*}{78.566} & 66 & 1957.947 & \multirow{2}{*}{-20.879} & 0.985 & 0.962 & 732.229 & 4.323 \\
\hline & & Predicted & 1937.067 & & 0.983 & 0.958 & 810.917 & 4.550 \\
\hline & \multirow{2}{*}{36.806} & 74 & $28,924.676$ & \multirow{2}{*}{-4.548} & 0.982 & 0.954 & 1.384 & 0.188 \\
\hline & & Predicted & $28,920.127$ & & 0.985 & 0.962 & 1.121 & 0.169 \\
\hline \multicolumn{9}{|c|}{$\mathrm{ACCSSP}=45 \mathrm{MPH}$} \\
\hline \multirow{4}{*}{$\begin{array}{c}\text { EST } \\
{[\mathrm{A} 1, \mathrm{~A} 2]}\end{array}$} & \multirow{2}{*}{71.384} & 65 & 350.128 & \multirow{2}{*}{-54.605} & 0.974 & 0.934 & 11.985 & 0.553 \\
\hline & & Predicted & 295.523 & & 0.981 & 0.952 & 8.216 & 0.458 \\
\hline & \multirow{2}{*}{33.8} & 71 & 8.335 & \multirow{2}{*}{-4.436} & 0.997 & 0.994 & 0.000 & 0.000 \\
\hline & & Predicted & 3.898 & & 0.984 & 0.959 & 0.002 & 0.007 \\
\hline \multirow{4}{*}{$\begin{array}{c}\text { ACRFP } \\
\text { (B) }\end{array}$} & \multirow{2}{*}{71.384} & 65 & 968.488 & \multirow{2}{*}{259.626} & 0.915 & 0.788 & 845.487 & 4.646 \\
\hline & & Predicted & 1228.114 & & 0.977 & 0.944 & 491.012 & 3.540 \\
\hline & \multirow{2}{*}{33.8} & 71 & $29,057.213$ & \multirow{2}{*}{0.462} & 0.998 & 0.996 & 0.000 & 0.000 \\
\hline & & Predicted & $29,057.675$ & & 0.887 & 0.717 & 0.000 & 0.002 \\
\hline \multicolumn{9}{|c|}{ ACCSSP $=55 \mathrm{MPH}$} \\
\hline \multirow{4}{*}{$\begin{array}{c}\text { EST } \\
{[\mathrm{A} 1, \mathrm{~A} 2]}\end{array}$} & \multirow{2}{*}{70.997} & 65 & 658.373 & \multirow{2}{*}{-72.241} & 0.969 & 0.922 & 4.957 & 0.356 \\
\hline & & Predicted & 586.131 & & 0.969 & 0.924 & 5.472 & 0.374 \\
\hline & 338 & 73 & 307.908 & & 0.967 & 0.917 & 1.839 & 0.217 \\
\hline & 30.0 & Predicted & 305.996 & -1.912 & 0.965 & 0.913 & 1.867 & 0.218 \\
\hline & 70997 & 65 & 2928.211 & & 0.970 & 0.925 & 2745.421 & 8.371 \\
\hline ACRFP & יונים או & Predicted & 2698.639 & & 0.974 & 0.936 & 2679.109 & 8.270 \\
\hline & 220 & 73 & $28,850.426$ & & 0.999 & 0.998 & 0.000 & 0.000 \\
\hline & 00.0 & Predicted & $28,848.251$ & & 0.997 & 0.993 & 0.000 & 0.001 \\
\hline & & & ACCSS & $=65 \mathrm{MPH}$ & & & & \\
\hline & 81095 & 67 & 505.586 & & 0.978 & 0.944 & 7.887 & 0.449 \\
\hline EST & 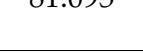 & Predicted & 474.242 & & 0.948 & 0.871 & 22.979 & 0.766 \\
\hline$[\mathrm{A} 1, \mathrm{~A} 2]$ & & 72 & 568.740 & & 0.970 & 0.924 & 1.279 & 0.181 \\
\hline & $3 / .4$ & Predicted & 572.750 & 4.009 & 0.968 & 0.921 & 1.292 & 0.182 \\
\hline & 81095 & 67 & 3078.741 & 269982 & 0.946 & 0.865 & 61.282 & 1.251 \\
\hline ACRFP & 01.093 & Predicted & 3348.724 & 209.902 & 0.961 & 0.901 & 92.636 & 1.538 \\
\hline (B) & 374 & 72 & $28,851.571$ & 0180 & 0.912 & 0.779 & 0.000 & 0.000 \\
\hline & $3 / .4$ & Predicted & $28,851.752$ & 0.100 & 0.989 & 0.971 & 0.000 & 0.000 \\
\hline
\end{tabular}


Table 8. Cont.

\begin{tabular}{|c|c|c|c|c|c|c|c|c|}
\hline Parameter & EAT $\left({ }^{\circ} \mathbf{F}\right)$ & CAT Profile $\left({ }^{\circ} \mathrm{F}\right)$ & Area & Conformance & $R^{2}$ & $\operatorname{Adj} R^{2}$ & SSE & RMSE \\
\hline \multicolumn{9}{|c|}{$\mathrm{ACCSSP}=75 \mathrm{MPH}$} \\
\hline \multirow{4}{*}{$\begin{array}{c}\text { EST } \\
{[\mathrm{A} 1, \mathrm{~A} 2]}\end{array}$} & \multirow{2}{*}{84.4} & 68 & 639.694 & \multirow{2}{*}{246.732} & 0.952 & 0.880 & 7.089 & 0.425 \\
\hline & & Predicted & 886.427 & & 0.952 & 0.879 & 28.418 & 0.852 \\
\hline & \multirow{2}{*}{37.40} & 70 & 669.610 & \multirow{2}{*}{-5.7879} & 0.966 & 0.915 & 2.408 & 0.248 \\
\hline & & Predicted & 663.822 & & 0.967 & 0.917 & 2.350 & 0.245 \\
\hline \multirow{4}{*}{$\begin{array}{c}\text { ACRFP } \\
\text { (B) }\end{array}$} & \multirow{2}{*}{84.4} & 68 & 2231.887 & \multirow{2}{*}{-782.45} & 0.919 & 0.797 & 383.320 & 3.128 \\
\hline & & Predicted & 1449.436 & & 0.909 & 0.773 & 1664.53 & 6.518 \\
\hline & \multirow{2}{*}{37.4} & 70 & $28,850.316$ & \multirow{2}{*}{0.065} & 0.999 & 0.996 & 0.000 & 0.000 \\
\hline & & Predicted & $28,850.381$ & & 0.925 & 0.813 & 0.000 & 0.000 \\
\hline
\end{tabular}

\section{Discussion}

In this research, the predictive model of CAT, one of the elements of DBV, is proposed. This article involved multiple concepts, developing the NARX DL model by mapping the elements VLV and CATOP (Section 2.1), defining the optimal HVAC criteria, predicting optimal CAT, and detailed validation using various test cases.

The properties of the NARX DL model are defined in Table S1, and its efficacy to predict CATOP vectors is validated using statistical techniques (RMSE, FOD, SNR), shown in Table 7. The test cases were developed with ACCSSP $=[3575] \mathrm{MPH}$ for the two datasets differentiated by EAT $>65^{\circ} \mathrm{F}$ and $<45^{\circ} \mathrm{F}$. The EST RMSE $<2.2$ for set 1 and $<0.95$ for set 2 , whereas ACRFP FOD $<11$ for set 1 and $<0.94$ for set 2 . In real-time, the values of [EST $\left.\left({ }^{\circ} \mathrm{F}\right), \mathrm{ACRFP}(\mathrm{PSI})\right]$ are always fluctuating, and hence the resulting SNR values are $<17$ for all cases, which depict acceptable noise. Despite the stochastic variation of the data, by visualising Figures 6 and 7 and Figures S1-S10, we observed that the predicted values fit the real-time curves. It is a well-known fact that extended training with multiple data sets would enhance the performance of the NARX DL model. Also, this article proposes the core concept of predicting the CAT profile by optimising CATOP elements. Therefore, the DL model is developed using default training properties and is assumed to produce acceptable results. Thus, we initiate the further steps of the project.

We selected the snippet with ACCSSP $=70 \mathrm{MPH}$ to initiate the testing, and the proposed methodology described in steps 4.1-4.4 (Figure 4) is adapted. The required input sets for the iterative analysis are generated using the equations defined in Table 1, and sample input sets are shown in Table 2. The optimal HVAC criteria proposed in Section 3 and Tables 3 and 4 are developed for estimating optimal CAT values for 10 steps $=100 \mathrm{~m}$. Thus, an optimal CAT matrix is developed shown in Table 5, executing the algorithm described in Section 4.4, and optimal CAT profiles are generated shown in Figures 8 and 9. Therefore, by fixing the initial value of CAT, a unique CAT profile has resulted, as shown in Figures 10 and 11.

To validate the proposed methodology, we developed the input sets with constant and predicted CAT profiles (Figures S11-S20), and these sets are fed into the NARX DL model. The results of the performance analysis comparing the constant and predicted CAT profiles are shown in Table 8 . The test case with ACCSSP $=75 \mathrm{MPH}, \mathrm{EAT}=84.4^{\circ} \mathrm{F}$, resulted in higher EST $=246.73\left({ }^{\circ} \mathrm{F}\right)$ for constant CAT $=68^{\circ} \mathrm{F}$ and predicted CAT profile has lower $\mathrm{ACRFP}=782.45$ (PSI). Whereas for $\mathrm{EAT}=37.4^{\circ} \mathrm{F}$, the predicted CAT has EST lower by $5.787\left({ }^{\circ} \mathrm{F}\right)$, and ACRFP has similar performance. The snippet with ACCSSP $=45 \mathrm{MPH}$, $\mathrm{EAT}=71.384^{\circ} \mathrm{F}$, resulted in ACRFP lowering by 259.626 (PSI) for constant $\mathrm{CAT}=65^{\circ} \mathrm{F}$, which is deviating the proposed concept, but the smoothness performance for predicted CAT has higher $\left[R^{2}, \operatorname{Adj} R^{2}\right]=[0.977$ 0.944] and lower [SSE RMSE] $=[491.013 .540]$. It is easy to see that the performance of the predicted CAT profile with test case ACCSSP $=55 \mathrm{MPH}$ 
has enhanced performance for all the parameters, and a similar explanation follows for the rest of the scenarios.

Therefore, the predicted CAT outperforms the constant CAT in maintaining the EST closer to $194{ }^{\circ} \mathrm{F}$ and ACRFP in the range of the threshold defined in Figure 3 [25] and Table S2. This approach satisfies the optimal HVAC criteria, and this enhances the EOC.

\section{Conclusions and Future Work}

In real-time, the DBV is defined by the three elements (Speeding, Steering, CAT), and variation of these parameters is the user's prerogative. In this manuscript, we proposed a new methodology to input the range of CAT and predict the optimal CAT profile, which could augment the HVAC functionality. The criteria of optimal HVAC were empirically developed using the elements (EST, ACRFP) predicted by the NARX DL model by mapping the elements VLV. We validated the NARX DL model by using real-time datasets and applied statistical techniques to the conformance of predicted and actual values.

The unique CAT profile was generated in the user-defined range, satisfying the constraints of optimal HVAC criteria. We prepared new input sets with the predicted and constant CAT profiles and fed them into the NARX DL model, which validates the predicted (EST, ACRFP) in the optimal desired range. The computational results obtained are satisfactory, and we quantified short snippets of distance $\left(1 \times 10^{3} \mathrm{~m}\right)$ for the speed ranges ACCSSP $=[2585] \mathrm{MPH}$. Also, the DL model generated smoother CAT profiles, and this method could derive a new functionality of inputting a range of user-defined set CAT to the HVAC system to enhance vehicle performance.

In this research, environmental factors (traffic congestion, solar reception (idling), HUM, ATP), HVAC parameters (compressor load, engine fan speed, power consumed), and human comfort elements (cabin moisture, multiple CAT inputs, psychrometric analysis) were not considered in the NARX DL model because of minimal variations and unavailability of the CAN data retrieved. Also, this project is confined to a single-vehicle test, that is, a 2020 Cadillac CT5 provided by GMC, and future work would involve developing the model to include all the affecting parameters and extend the validation using multiple vehicle test cases.

Supplementary Materials: The following are available online at https:/ /www.mdpi.com/article/10.3 390/vehicles3040052/s1. The Supplementary Materials validating the DL model and predicted CAT profiles for multiple test cases are added for this article. Please refer to the Tables S1 and S2, and Figures S1-S20.

Author Contributions: S.K., came up with the idea, developed the concept, and performed the analysis. H.M. is the principal investigator for this project. All authors have read and agreed to the published version of the manuscript.

Funding: The project "Prediction of CAT" was performed under the research collaboration of the University of Michigan and GMC, funded by William J. Clifford (Director) of the Systems Engineering department at GMC.

Institutional Review Board Statement: Not applicable.

Informed Consent Statement: Not applicable.

Data Availability Statement: The data used in this work are proprietary to GMC and cannot be made publicly available. However, the modelling algorithm is available on request.

Acknowledgments: The authors would like to thank Iqbal Surti, Systems Engineer at GMC, for his assistance in real-time testing. The technical analysis was performed using the tools provided by GMC (Vehicle Spy and neoVI) and the University of Michigan (MATLAB).

Conflicts of Interest: The authors of this manuscript declare that there is no conflict of interest regarding the publication of this article. 


\section{Abbreviations}

ACC

ACCSSP

ACRFP

ACS

ATP

CAN

CAT

CATOP

DBV

DL

EAT

EOC

EOP

EST

FOD

GMC

HUM

HVAC

ISB

LAT

LOT

MSE

NARX

RMSE

RRC

SL

SNR

SSE

StdDev

VLV

YAR

Nomenclature

$A_{c}$

bar

$C_{d}$

${ }^{\circ} \mathrm{C}$

$\operatorname{deg} \cdot \mathrm{s}^{-1}$

${ }^{\circ} \mathrm{F}$

$\mathrm{g}$

$\mathrm{Hz}$

$\mathrm{Kg}$

$\mathrm{Km}$

$\mathrm{kPa}$

$L_{a(k)}$

$L_{o(k)}$

$M_{\mathcal{C}}$

$M_{L}$

$\mathrm{MPH}$

$\mathrm{m}$

$\mathrm{m}^{2}$

$\mathrm{m} \cdot \mathrm{s}^{-2}$

$\mathrm{ms}$

$\mu_{r}$

PSI
Adaptive cruise control

Adaptive cruise control set speed profile (MPH)

Air conditioning refrigerant fluid pressure (PSI)

Air conditioning system

Atmospheric pressure ( 1.01325 bar)

Controller area network

Cabin air temperature $\left({ }^{\circ} \mathrm{F}\right)$

Cabin air temperature operating point

Driver behaviour vector

Deep learning

External air temperature $\left({ }^{\circ} \mathrm{F}\right)$

Engine operating conditions

Engine operating point

Engine surface temperature $\left({ }^{\circ} \mathrm{F}\right)$

First-order derivative

General Motors Company

Humidity (\%rh)

Heating, ventilation, and air conditioning

Ideal steering behaviour

Lateral acceleration $\left(\mathrm{m} \cdot \mathrm{s}^{-2}\right)$

Longitudinal acceleration $\left(\mathrm{m} \cdot \mathrm{s}^{-2}\right)$

Mean square error

Nonlinear autoregressive network with exogenous inputs

Root mean square error

Radius of road curvature (m)

Speed limit (MPH)

Signal to noise ratio

Sum of squares of error

Standard Deviation

Vehicle level vectors

Yaw Rate $\left(\mathrm{rad} \cdot \mathrm{s}^{-1}\right)$

Area of vehicle cross-section $\left(\mathrm{m}^{2}\right)$

$1 \mathrm{bar}=100 \mathrm{kPa}$

Aerodynamic drag coefficient. 2020 Cadillac CT5 ( 0.31)

Centigrade

Degrees per second

Fahrenheit

Gravity $\left(9.8 \mathrm{~m} \cdot \mathrm{s}^{-2}\right)$

Hertz

Kilogram

Kilometres

Kilo pascals

Lateral acceleration at time step $\mathrm{k}\left(\mathrm{m} \cdot \mathrm{s}^{-2}\right)$

Longitudinal acceleration at time step $\mathrm{k}\left(\mathrm{m} \cdot \mathrm{s}^{-2}\right)$

Mass of the vehicle. 2020 Cadillac CT5 $(\mathrm{kg})$

Mass of the additional load (kg)

Miles per hour

Metres

Metre square

Metres per second square.

Milli seconds

Rolling coefficient $(\sim 0.013)$

Pound per square inch 


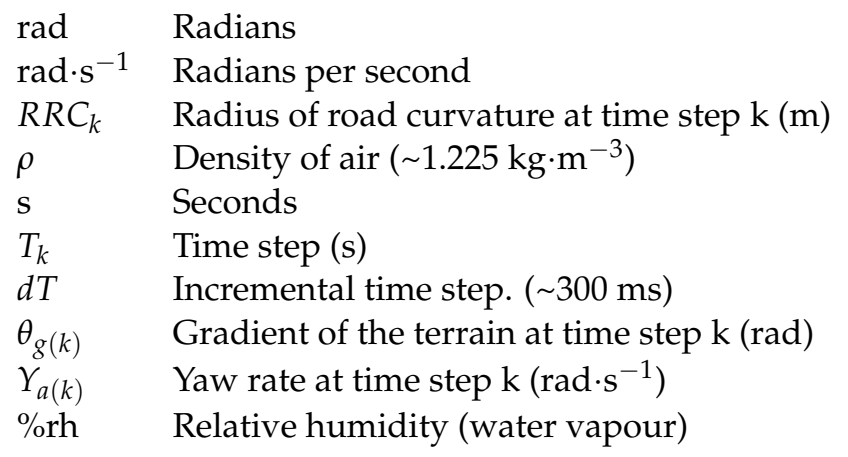

\section{References}

1. Holweg, M. The evolution of competition in the automotive industry. In Build to Order; Springer: London, UK, 2008 ; pp. 13-34.

2. Farrington, R.; Rugh, J. Impact of Vehicle Air-Conditioning on Fuel Economy, Tailpipe Emissions, and Electric Vehicle Range (No. NREL/CP-540-28960); National Renewable Energy Lab: Golden, CO, USA, 2000.

3. Khayyam, H.; Kouzani, A.Z.; Hu, E.J.; Nahavandi, S. Coordinated energy management of vehicle air conditioning system. Appl. Therm. Eng. 2011, 31, 750-764. [CrossRef]

4. Johnson, V.H. Fuel Used for Vehicle Air Conditioning: A State-by-State Thermal Comfort-Based Approach (No. 2002-01-1957); SAE Technical Paper; SAE International: Warrendale, PA, USA, 2002.

5. Lee, J.; Kim, J.; Park, J.; Bae, C. Effect of the air-conditioning system on the fuel economy in a gasoline engine vehicle. Proc. Inst. Mech. Eng. Part D J. Automob. Eng. 2013, 227, 66-77. [CrossRef]

6. Khayyam, H. Adaptive intelligent control of vehicle air conditioning system. Appl. Therm. Eng. 2013, 51, 1154-1161. [CrossRef]

7. Nasution, H. Development of fuzzy logic control for vehicle air conditioning system. Telkomnika 2008, 6, 73. [CrossRef]

8. Khayyam, H.; Abawajy, J.; Jazar, R.N. Intelligent energy management control of vehicle air conditioning system coupled with engine. Appl. Therm. Eng. 2012, 48, 211-224. [CrossRef]

9. Khayyam, H.; Kouzani, A.Z.; Hu, E.J. Reducing energy consumption of vehicle air conditioning system by an energy management system. In Proceedings of the 2009 IEEE Intelligent Vehicles Symposium, Xi'an, China, 3-5 June 2009; pp. 752-757.

10. Huang, K.D.; Tzeng, S.C.; Jeng, T.M.; Chiang, W.D. Air-conditioning system of an intelligent vehicle-cabin. Appl. Energy 2006, 83, 545-557. [CrossRef]

11. Fayazbakhsh, M.A.; Bahrami, M. Comprehensive Modeling of Vehicle Air Conditioning Loads Using Heat Balance Method; SAE Technical Paper; SAE International: Warrendale, PA, USA, 2013; Volume 2013, p. 1507.

12. Cvok, I.; Ratkovic, I.; Deur, J. Optimization of Control Parameters of Vehicle Air-Conditioning System for Maximum Efficiency (No. 2020-01-1242); SAE Technical Paper; SAE International: Warrendale, PA, USA, 2020.

13. Kolachalama, S.; Malik, H. Predictive Model of Adaptive Cruise Control Speed to Enhance Engine Operating Conditions. Vehicles 2021, 3, 749-763. [CrossRef]

14. Kolachalama, S.; Lakshmanan, S. Using Deep Learning to Predict the Engine Operating Point in Real-Time (No. 2021-01-0186); SAE Technical Paper; SAE International: Warrendale, PA, USA, 2021.

15. Wang, W.; Xi, J.; Chen, H. Modeling and recognizing driver behavior based on driving data: A survey. Math. Probl. Eng. 2014, 2014, 1-20. [CrossRef]

16. Kolachalama, S.; Kuppa, K.; Mattam, D.; Shukla, M. Thermal Analysis of Radiator Core in Heavy Duty Automobile. In Proceedings of the Heat Transfer Summer Conference, Jacksonville, FL, USA, 10-14 August 2008; Volume 48487, pp. 123-127.

17. Eathakota, V.; Singh, A.K.; Kolachalam, S.; Krishna, K.M. Determination of optimally stable posture for force actuator based articulated suspension for rough terrain mobility. In Proceedings of the FIRA RoboWorld Congress, Bangalore, India, 15-17 September 2010; Springer: Berlin/Heidelberg, Germany, 2010; pp. 154-161.

18. Talom, H.L.; Beyene, A. Heat recovery from automotive engine. Appl. Therm. Eng. 2009, 29, 439-444. [CrossRef]

19. Yan, X.; Fleming, J.; Lot, R. A/C energy management and vehicle cabin thermal comfort control. IEEE Trans. Veh. Technol. 2018, 67, 11238-11242. [CrossRef]

20. Roberts, A.; Brooks, R.; Shipway, P. Internal combustion engine cold-start efficiency: A review of the problem, causes and potential solutions. Energy Convers. Manag. 2014, 82, 327-350. [CrossRef]

21. Borman, G.; Nishiwaki, K. Internal combustion engine heat transfer. Prog. Energy Combust. Sci. 1987, 13, 1-46. [CrossRef]

22. Autozone: Air Conditioning Pressure Chart; R134a-Refrigerant; California Air Ressources Board (CARB): Sacramento, CA, USA, 2009.

23. Kolachalama, S.; Hay, C.L.; Mushtarin, T.; Todd, N.; Heitman, J.; Hermiz, S. An Algorithm to Estimate Steering Behavior Using Vehicle Radius Of Curvature, 647068, Research Disclosure; Questel Ireland Ltd.: Paris, France, 2018.

24. Xing, W.; Chen, H.; Ding, H. The application of controller area network on vehicle. In Proceedings of the IEEE International Vehicle Electronics Conference (IVEC'99)(Cat. No. 99EX257), Changchun, China, 9 September 1999; pp. 455-458.

25. Gallardo, F.B. Extraction and Analysis of Car Driving Data Via OBD II. Ph.D. Thesis, Miguel Hernández University of Elche, Alicante, Spain, 2018. 
26. Benmimoun, M.; Pütz, A.; Zlocki, A.; Eckstein, L. Effects of acc and fcw on speed, fuel consumption, and driving safety. In Proceedings of the 2012 IEEE Vehicular Technology Conference (VTC Fall), Quebec City, QC, Canada, 3-6 September 2012; pp. 1-6.

27. Eathakota, V.P.; Kolachalama, S.; Krishna, K.M.; Sanan, S. Optimal posture control for force actuator based articulated suspension vehicle for rough terrain mobility. In Advances in Mobile Robotics; World Scientific: Coimbra, Portugal, 2008; pp. 760-767. 